\title{
BMJ Open Longitudinal humoral antibody response to SARS-CoV-2 infection among healthcare workers in a New York City hospital
}

\author{
Vidya Menon (D) , ${ }^{1}$ Masood A Shariff (D , , Victor Perez Gutierrez, ${ }^{1}$ Juan M Carreño, ${ }^{2}$ \\ Bo Yu, ${ }^{1}$ Muzamil Jawed, ${ }^{1}$ Marcia Gossai, ${ }^{1}$ Elisenda Valdez, ${ }^{1}$ Anjana Pillai, ${ }^{1}$ \\ Usha Venugopal, ${ }^{1}$ Moiz Kasubhai, ${ }^{1}$ Vihren Dimitrov, ${ }^{1}$ Florian Krammer $^{2}$
}

To cite: Menon V, Shariff MA, Perez Gutierrez V, et al. Longitudinal humoral antibody response to SARS-CoV-2 infection among healthcare workers in a New York City hospital. BMJ Open 2021;11:e051045. doi:10.1136/ bmjopen-2021-051045

- Prepublication history and additional supplemental material for this paper are available online. To view these files, please visit the journal online (http://dx.doi.org/10.1136/ bmjopen-2021-051045).

Received 09 March 2021 Accepted 22 September 2021

Check for updates

(C) Author(s) (or their employer(s)) 2021. Re-use permitted under CC BY-NC. No commercial re-use. See rights and permissions. Published by BMJ.

${ }^{1}$ Department of Medicine, New York City Health and Hospitals/ Lincoln, New York City, New York, USA

${ }^{2}$ Department of Microbiology, Icahn School of Medicine at Mount Sinai, New York City, New York, USA

Correspondence to

Dr Vidya Menon;

menonv@nychhc.org

\section{ABSTRACT}

Objective Dynamics of humoral immune responses to SARS-CoV-2 antigens following infection suggest an initial decay of antibody followed by subsequent stabilisation. We aim to understand the longitudinal humoral responses to SARS-CoV-2 nucleocapsid (N) protein and spike (S) protein and to evaluate their correlation to clinical symptoms among healthcare workers (HCWs).

Design A prospective longitudinal study.

Setting This study was conducted in a New York City public hospital in the South Bronx, New York.

Participants HCWs participated in phase $1(\mathrm{~N}=500)$ and were followed up 4 months later in phase $2(\mathrm{~N}=178)$ of the study. They underwent SARS-CoV-2 PCR and serology testing for $\mathrm{N}$ and $\mathrm{S}$ protein antibodies, in addition to completion of an online survey in both phases. Analysis was performed on the 178 participants who participated in both phases of the study.

Primary outcome measure Evaluate longitudinal humoral responses to viral $\mathrm{N}$ (qualitative serology testing) and S protein (quantitative Mount Sinai Health System ELISA to detect receptor-binding domain and full-length S reactive antibodies) by measuring rate of decay.

Results Anti-N antibody positivity was $27 \%$ and anti-S positivity was $28 \%$ in phase 1 . In phase 1 , anti-S titres were higher in symptomatic (6754 (5177-8812)) than in asymptomatic positive subjects (5803 (2825-11 920)). Marginally higher titres (2382 (1494-3797)) were seen in asymptomatic compared with the symptomatic positive subgroup (2198 (1753-2755)) in phase 2. A positive correlation was noted between age $(R=0.269, p<0.01)$, number $(\mathrm{R}=0.310, \mathrm{p}<0.01)$ and duration of symptoms $(R=0.434, p<0.01)$, and phase 1 anti-S antibody titre. A strong correlation $(R=0.898, p<0.001)$ was observed between phase 1 titres and decay of anti-S antibody titres between the two phases. Significant correlation with rate of decay was also noted with fever $(R=0.428, p<0.001)$, gastrointestinal symptoms ( $R=0.340, p<0.05)$, and total number $(R=0.357, p<0.01)$ and duration of COVID-19 symptoms $(R=0.469, p<0.001)$.

Conclusions Higher initial anti-S antibody titres were associated with larger number and longer duration of symptoms as well as a faster decay between the two time points.

\section{STRENGTHS AND LIMITATIONS OF THIS STUDY}

$\Rightarrow$ The strength of our study is the longitudinal design with serial sampling to determine humoral response to SARS-CoV-2 infection from consenting healthcare workers during the pandemic.

$\Rightarrow$ This study collected serial detailed characteristics of symptomatic and asymptomatic healthcare workers to correlate with durability and decay of humoral response.

$\Rightarrow$ This study is limited by representation of only a single institution's data and the possibility of recall bias to the responses on the online survey.

$\Rightarrow$ Our cohort for phase 2 was smaller than phase 1 , due to discontinuation of volunteer healthcare workers from the surge period.

\section{INTRODUCTION}

In light of the unprecedented COVID-19 pandemic, understanding the role of the immune system in countering the viral infection is critical not just to design effective antiviral strategies but also to aid us in taking appropriate public health decisions. The early publication of the viral genome led to a rapid development of many nucleic acid-based diagnostic assays for SARS-CoV-2 infections. While nucleic acid-based tests are widely employed in the diagnosis of acute (current) SARS-CoV-2 infections, they are often limited in their clinical utility in identifying past infections or assessing the level of immunity to SARSCoV-2 within the communities. Evaluation of antibody responses is the other well-known modality used in a clinical setting that can detect both current and past infections, and is the preferred approach for surveillance to determine the true prevalence of infections. The currently available serological assays for SARS-CoV-2 target either the viral nucleoprotein $(\mathrm{N})$ or the spike surface protein $(\mathrm{S})$ antigens. The $\mathrm{S}$ protein, which contains the 
receptor-binding domain (RBD), binds to host cells via the ACE2 receptor, followed by membrane fusion. ${ }^{12}$ The $\mathrm{S}$ is the target of most neutralising antibodies,${ }^{3-5}$ while the $\mathrm{N}$ plays an important role in transcription enhancement and viral assembly. ${ }^{6}$ Studies have demonstrated that antibodies against the $\mathrm{N}$ and $\mathrm{S}$ appeared around the same timebetween day 8 and day 14 after the onset of symptoms with antibodies to the $\mathrm{N}$ being more sensitive than anti-S antibodies for detecting early infection. ${ }^{7}$ Neutralising antibodies confer protective immunity and can be detected in most infected individuals 10-15 days following the onset of COVID-19 symptoms and remain elevated following initial viral clearance. ${ }^{8-12}$ There is compelling evidence to suggest that serological assays for anti-S antibodies predict neutralising activity, in contrast to N-based assays. ${ }^{113}$

The detailed characterisation of the dynamics of humoral immune responses to the SARS-CoV-2 viral antigens following infection is still ongoing and early evidence suggests an initial decay of antibody followed by stabilisation at a certain level. ${ }^{11}{ }^{14-18}$ These dynamics are likely driven by an initial expansion of plasmablasts which produce large amounts of antibody but die off quickly followed by a slower decay of antibody titres (the half-life of IgG is approximately 3 weeks) which then transitions into a steady state level of antibody produced by longlived plasma cells. ${ }^{19}$ However, it is currently unknown if the magnitude of the initial expansion of plasmablast and the associated antibody titres are correlated with the steady state level of serum antibody produced by longlived plasma cells. This is an important question since steady state antibody levels may provide superior protection from reinfection. ${ }^{2021}$

Specifically, there is currently a paucity of information on the kinetics of antibody decay among healthcare workers (HCWs). It is suspected that SARS-CoV-2 infections among HCWs are usually asymptomatic or mildly symptomatic and frequently associated with either underreporting of symptoms or heterogeneous PCR and/or serological diagnostics leading to most of them going undetected or unrecognised. ${ }^{22}$ A large cohort study of HCWs in the greater New York City (NYC) area showed a seroprevalence of SARS-CoV-2 antibodies of $13.7 \% .{ }^{23}$ Our own data of anti-N antibody screening among HCWs at an NYC public hospital in the Bronx following the first 'surge' of COVID-19 in May 2020 found that SARS-CoV-2 seroprevalence was at $27 \% .{ }^{24}$ Understanding the longitudinal kinetics of SARS-CoV-2 antibody response and the effectiveness of commercial antibody measurement assays is crucial to correctly determine infection rates, seroprevalence and true seroreversion rates in both infected and vaccinated individuals-and to better understand protection associated with sero-positivity.

In this study, we aimed to investigate the longitudinal humoral responses to viral $\mathrm{N}$ and the $\mathrm{S}$ protein and to evaluate their correlation to clinical symptoms and baseline characteristics of the HCW cohort. We also evaluated if initial high antibody levels correlated with high antibody titres at steady state.
METHODS

\section{Study setting and population}

This is a prospective longitudinal study done in two phases after receiving Institutional Review Board approval. The phase 1 study was conducted in May/June 2020 and the phase 2 was completed August/September 2020. The cohort included HCWs who worked at the NYC public hospital in the South Bronx. Information about the study was disseminated among HCWs via hospital's intranet bulletins, by research staff approaching on duty staff and handing out study flyers and introducing the study in multiple department meetings. The HCWs who had participated in phase 1 were called individually to schedule an appointment with research staff for bloodwork and survey completion for phase 2 study.

In the phase 1 of the study, after informed consent, participants underwent qualitative serology testing (Abbott Architect SARS-CoV-2 IgG Assay, Abbott Park, Illinois, USA) ${ }^{25}$ and a nasopharyngeal swab for SARSCoV-2 (Bio-Reference Laboratories, Elmwood Park, New Jersey, USA). They also completed an initial online survey on demographics, symptoms of COVID-19 including duration and healthcare/community exposure. An extra sample was collected and stored at $-80^{\circ} \mathrm{C}$ for subsequent analysis. These samples were processed using a quantitative ELISA, developed by Mount Sinai Health System (MSH ELISA), ${ }^{27}$ that correlates well with virus neutralisation, to detect RBD and full-length $S$ reactive antibodies. In phase 2 of the study, consenting HCWs underwent qualitative and quantitative serology assessment by Abbott and MSH ELISA tests, respectively. They also completed a follow-up online survey including information about demographics, interval SARS-CoV-2 PCR positivity and healthcare/community exposure.

\section{Antibody assays}

The Abbott Architect assay uses a qualitative chemiluminescent microparticle immunoassay technology targeting the $\mathrm{N}$ antigen of the virus with a reported sensitivity of $100 \%$ (CI $95.8 \%$ to $100 \%$ ) and specificity of $99.6 \%$ (CI $99 \%$ to $99.9 \%) .{ }^{25}$ The MSH ELISA consists of an initial ELISA using serum or plasma to detect specific IgG against the RBD of SARS-CoV-2 at a single dilution, followed by quantitative titrations of presumptive positives in a confirmatory ELISA against full length SARS-CoV-2 S protein. ${ }^{28}$ The positive result from the S ELISA is reported as antibody at a titre of 1:80 or higher. Test performance assessment revealed that PCR +samples were $94 \%$ positive and all negative samples returned a negative result for $100 \%$ negative agreement. ${ }^{29}$

\section{Survey}

The open-access online SurveyMonkey tool (SurveyMonkey, San Mateo, California, USA; http://www. surveymonkey.com) was used to create and administer our survey to participating HCWs. The survey in both phases was developed with feedback from the research team. Open-text questions were minimised. Preliminary 
versions of the survey were piloted among a focus group of 10 healthcare providers, and their feedback about length, flow, ease of response and acceptability to respondents was incorporated to finalise the version administered to the participants. The online survey was accessed by a unique identification number assigned to each participant, blinded to the research team to ensure confidentiality. The phase 1 survey was designed to capture demographics and current medical history, number and duration of symptoms of COVID-19 infection (exposure during the pandemic prior to phase 1), domestic/international travel, and healthcare and community exposure. ${ }^{24}$ The risk of exposure in the healthcare setting and community exposure was determined based on Centers for Disease Control and Prevention guidelines. ${ }^{30}$

The phase 2 survey requested information on new comorbidities, persistent COVID-19 symptoms (cough, shortness of breath, anosmia, ageusia, myalgia, nausea and/or diarrhoea), interim testing via antibody and/or reverse transcription PCR (if present) and their result (positive/negative), presence of positive SARS-CoV-2 PCR results in the preceding months (exposure after phase 1 sample collection), interim domestic/international travel and continued use of personal protective equipment. Both surveys have been attached as online supplemental materials.

\section{Statistical analysis}

Convenience sampling design was adapted to recruit participants with a goal of 500 participants. Descriptive statistics were used to summarise the baseline characteristics of the cohort and key study outcome variables. Categorical variables were compared by the $\mathrm{X}^{2}$ test, while continuous variables were compared by a Student's t-test. The $\mathrm{S}$ antibody titres were described as geometric means. Correlations were calculated using standard Pearson's and Spearman's correlation. Multiple linear regression was applied to determine the predictors of $\log 10$ rate of decay from phase 1 to phase 2 of anti-S antibodies. A p value of $<0.05$ was considered significant. All statistical analyses were performed using SPSS V.27 (IBM).

\section{Patient and public involvement}

Patients or the public were not involved in the design, or conduct, or reporting, or dissemination plans of our research.

\section{RESULTS}

For phase 1 of the study, 500 HCWs underwent both PCR and serology testing. Of these, 137 were positive for anti-N antibody (Abbott) and 142 were positive by the MSH ELISA. In the phase 2, 178 participants from the initial cohort consented to participate and underwent PCR and serology testing. The interval between phase 1 and phase 2 was $133 \pm 21$ days. The details of patient enrolment are described in figure 1 . While 46 of the 178 tested subjects remained positive for the anti-N antibody (Abbott), 70 were positive by the MSH ELISA in the second phase. Anti-S titres of the five subjects in the first phase were close to the cut-off for positivity. Twenty-two subjects who were negative for anti-N antibody in phase 2 had positive titres of anti-RBD and anti-S antibodies, though lower than their phase 1 levels. Among the subjects who participated in the phase 1 and phase 2 study, 68 were positive in both phases by the MSH ELISA, 110 were negative in both phases and 2 were positive only in phase 2 with previously negative results in phase 1 .

The baseline characteristics of study participants who were positive by MSH ELISA in both phases $(n=68)$ and those who were negative in both phases $(n=108)$ are shown in table 1 . The mean age of the participants was $44.7 \pm 12.4$ years, and $63.1 \%$ were female. Overall, $30.7 \%$ of the HCWs were Latinx, $29.5 \%$ were Asian, $16.5 \%$ were black and $17.6 \%$ were white. COVID-19-related symptoms were present in $83.8 \%$ (57) of the subjects who were positive in both phases, while only $42.6 \%$ (46) of the subgroup who had negative antibodies in both phases admitted to symptoms prior to phase 1 . The duration of symptoms prior to phase 1 was longer among the symptomatic positive group ( $48.3 \%$ for $>14$ days) in comparison with symptomatic negative group ( $17.8 \%$ for $>14$ days). The mean duration of symptoms to phase 1 testing in the symptomatic positive subcohort was $47.9 \pm 16.0$ days. Persisting symptoms of COVID-19 were reported in 19 (27.9\%) subjects from the cohort with positive antibodies in both phases.

\section{Clinical characteristics and seropositivity to $S$ protein in both phases}

Table 2 describes the characteristics of the symptomatic and asymptomatic subjects who were positive for anti-S antibody in both phases. Baseline characteristics were comparable between the groups and no difference either in the healthcare or community exposure or in the location of work (emergency department/inpatient/intensive care unit, Operating Room, etc) between the two groups was observed. Titres of anti-S antibodies (geometric mean area under the curve (AUC)) were higher in symptomatic subjects than in asymptomatic positive subjects (6754 AUC vs 5803 AUC) in phase 1. However, in the phase 2 analysis, we observed marginally higher titres in the asymptomatic subgroup compared with the symptomatic subgroup (2383 AUC vs 2198 AUC). Figure 2 illustrates the symptomatic and asymptomatic antibody levels of anti-S antibodies. The rate of decay was higher in the symptomatic subgroup (geometric mean 32.96 per day) compared with the asymptomatic (geometric mean 23.42 per day) suggesting delayed antibody/kinetics in the asymptomatic cohort.

\section{Phase 1 anti-S antibody titre and clinical correlations}

A Pearson's product and Spearman's rank-order correlation were run to assess the relationship between cohort characteristics including age, gender, comorbidities, number of symptoms of COVID-19, healthcare exposure and phase 1 anti-S titres in our cohort (figure 3). One 

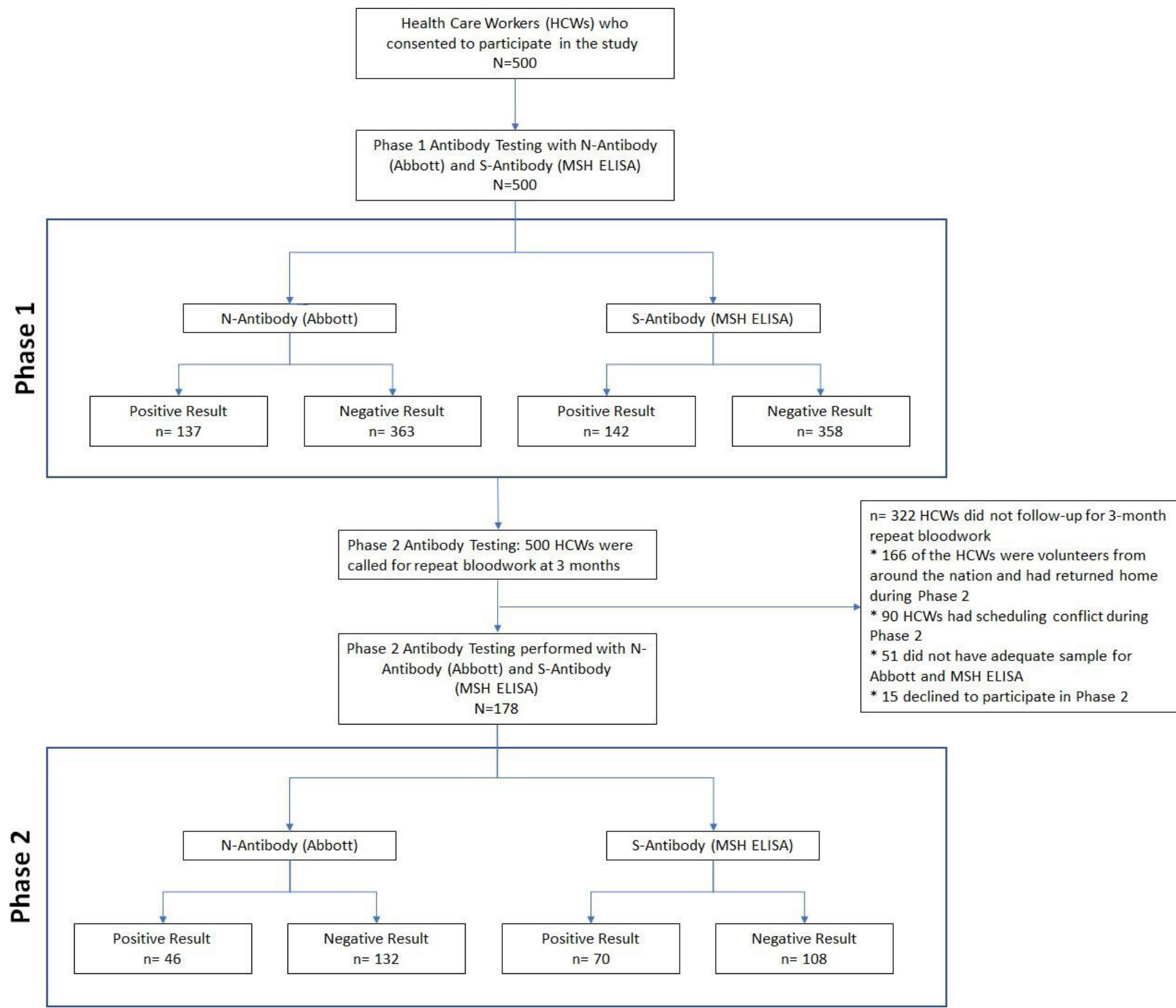

Figure 1 Flow chart of patient enrolment, follow-up and analysis. MSH, Mount Sinai Health System.

hundred forty-three subjects with a positive test in phase 1 were included in the analysis. Scatter plot analysis showed a monotonic relationship between the variables. A statistically significant weak positive correlation was observed between age and phase 1 anti-S antibody titres $(\mathrm{R}=0.269$, $\mathrm{p}<0.01)$. Moderate positive correlation was present between presence of fever $(\mathrm{R}=0.319, \mathrm{p}<0.01)$, number of symptoms $(\mathrm{R}=0.310, \mathrm{p}<0.01)$ and days of symptoms $(\mathrm{R}=0.434, \mathrm{p}<0.01)$ and anti-S antibody titre; and weak positive correlation was observed with upper respiratory symptoms $(\mathrm{R}=0.278, \mathrm{p}<0.01)$ and gastrointestinal $(\mathrm{GI})$ symptoms $(\mathrm{R}=0.204, \mathrm{p}<0.05)$ with anti-S antibody titres.

\section{Correlation of rate of decay of anti-S antibody titres from phase 1 to phase 2 and clinical characteristics}

Results of Pearson's correlation to assess the relationship between cohort characteristics including phase 1 anti-S antibody titres, age, gender, comorbidities, symptoms of COVID-19, number of symptoms of COVID-19, healthcare exposure and decay of anti-S titres between the two phases in our cohort are shown in figure 4. A strong positive statistically significant correlation was observed between phase 1 titres and decay of anti-S antibody titres between the two phases $(\mathrm{R}=0.898, \mathrm{p}<0.001)$. Medium positive correlation was observed between presence of fever $(\mathrm{R}=0.428, \mathrm{p}<0.001)$, GI symptoms $(\mathrm{R}=0.340$, $\mathrm{p}<0.05)$, number of symptoms $(\mathrm{R}=0.357, \mathrm{p}<0.01)$, duration of symptoms $(\mathrm{R}=0.469, \mathrm{p}<0.001)$ with decay of anti-S antibody titres between the two phases, respectively.

A pairwise comparison was performed between rate of decay of anti-S antibody titres and patient characteristics (figure 5). Rate of decay by gender was comparable (male; $30.73 \mathrm{AUC} /$ day vs female; $34.68 \mathrm{AUC} /$ day, $\mathrm{p}=0.413)$. Asians (86.0 AUC/day) demonstrated a higher rate of decay compared with white (7.2 AUC/day) and black (19.61 AUC/day) individuals; while Latinx (47.28 AUC/day) race had higher rate of decay compared with 
Table 1 Broad characteristics among healthcare workers assessed for antibody reactivity to spike SARS-CoV-2 protein in phase 1 and phase 2

\begin{tabular}{|c|c|c|c|c|}
\hline & Overall* & $\begin{array}{l}\text { Spike ELISA } \\
\text { (AUC) positive in } \\
\text { both phases }\end{array}$ & $\begin{array}{l}\text { Negative reactivity to } \\
\text { spike (AUC) in both } \\
\text { phases }\end{array}$ & $P$ value \\
\hline & $\mathrm{N}=176$ & $\mathrm{n}=68$ & $\mathrm{n}=108$ & \\
\hline Age, years & $44.7 \pm 12.4$ & $42.9 \pm 11.9$ & $45.8 \pm 12.7$ & 0.099 \\
\hline Female, gender & $111(63.1 \%)$ & $40(58.8 \%)$ & $71(65.7 \%)$ & 0.467 \\
\hline Race & & & & 0.666 \\
\hline Latinx & $54(30.7 \%)$ & $21(30.9 \%)$ & $33(30.6 \%)$ & \\
\hline Asian & $52(29.5 \%)$ & $18(26.5 \%)$ & $34(31.5 \%)$ & \\
\hline Black & $29(16.5 \%)$ & $15(22.1 \%)$ & $14(13.0 \%)$ & \\
\hline White & $31(17.6 \%)$ & $10(14.7 \%)$ & $21(19.4 \%)$ & \\
\hline Other & $10(5.7 \%)$ & $4(5.9 \%)$ & $6(5.9 \%)$ & \\
\hline Comorbidities & $54(30.7 \%)$ & $25(36.8 \%)$ & $29(26.9 \%)$ & 0.214 \\
\hline BCG vaccine received in childhood & $87(49.4 \%)$ & $35(51.5 \%)$ & $52(48.1 \%)$ & 0.902 \\
\hline COVID-19-related symptoms prior to phase 1 & $103(58.5 \%)$ & $57(83.8 \%)$ & $46(42.6 \%)$ & $<0.001$ \\
\hline Duration of symptoms & & & & $<0.001$ \\
\hline$<7$ days & $48(46.6 \%)$ & $18(31.0 \%)$ & $30(66.7 \%)$ & \\
\hline $7-14$ days & $19(18.4 \%)$ & $12(20.7 \%)$ & $7(15.6 \%)$ & \\
\hline$>14$ days & $36(35.0 \%)$ & $28(48.3 \%)$ & $8(17.8 \%)$ & \\
\hline Time from symptom to positive result, days & $45.7 \pm 19.9$ & $47.9 \pm 16.0$ & $42.9 \pm 24.1$ & 0.062 \\
\hline $\begin{array}{l}\text { RT-PCR positive result for SARS-CoV-2 prior to } \\
\text { phase } 1\end{array}$ & $51(29.0 \%)$ & $49(72.1 \%)$ & $2(1.9 \%)$ & $<0.001$ \\
\hline $\begin{array}{l}\text { RT-PCR positive result for SARS-CoV-2 during } \\
\text { phase } 1\end{array}$ & $14(8.0 \%)$ & $13(19.1 \%)$ & $1(0.9 \%)$ & $<0.001$ \\
\hline Persisting symptoms from COVID-19 & $25(14.2 \%)$ & $19(27.9 \%)$ & $6(5.6 \%)$ & $<0.001$ \\
\hline Nature of work & & & & 0.306 \\
\hline Physicians & $81(46.0 \%)$ & $29(42.6 \%)$ & $52(51.5 \%)$ & \\
\hline Nurses & $29(16.5 \%)$ & $15(22.1 \%)$ & $14(13.0 \%)$ & \\
\hline Others & $64(36.4 \%)$ & $24(35.3 \%)$ & $40(39.6 \%)$ & \\
\hline \multicolumn{5}{|l|}{ Hospital areas worked in } \\
\hline Emergency department/inpatient units & $118(67.0 \%)$ & $50(73.5 \%)$ & $68(63.0 \%)$ & 0.141 \\
\hline Ambulatory care/clinics & $72(40.9 \%)$ & $27(39.7 \%)$ & $45(41.7 \%)$ & 0.631 \\
\hline Administration/non-clinical care areas & $24(13.6 \%)$ & $9(13.2 \%)$ & $15(13.9 \%)$ & 0.867 \\
\hline Community exposure & $47(26.7 \%)$ & $19(27.9 \%)$ & $28(25.9 \%)$ & 0.591 \\
\hline Household exposure & $39(22.2 \%)$ & $17(25.0 \%)$ & $22(20.4 \%)$ & 0.343 \\
\hline PPE use at work & $173(98.3 \%)$ & $67(98.5 \%)$ & $106(98.1 \%)$ & 0.226 \\
\hline Use of face mask outside of the hospital & $158(89.8 \%)$ & $58(85.3 \%)$ & $100(92.6 \%)$ & 0.062 \\
\hline
\end{tabular}

Continuous variables are expressed as mean (SD), categorical variables as $\mathrm{n}(\%)$.

${ }^{*}$ Demographic data are missing for two participants from the overall cohort.

AUC, area under the curve; PPE, personal protective equipment; RT-PCR, reverse transcription PCR.

white (7.2 AUC/day) individuals. Subjects with fever had a higher rate of decay than those who did not report fever (53.08 AUC/day vs 16.14 AUC/day, $\mathrm{p}<0.01$ ). Similarly, subjects with GI symptoms had a higher rate of decay than those without $(55.81 \mathrm{AUC} /$ day vs $21.94 \mathrm{AUC} /$ day, $\mathrm{p}<0.05)$. Subjects with symptoms restricted to less than 7 days demonstrated a lower rate of decay when compared with symptomatic subjects over 7-14days (13.60 AUC/ day vs $36.12 \mathrm{AUC} /$ day, $\mathrm{p}<0.05)$ and when compared with symptomatic subjects with more than 14 days (13.60 AUC/day vs $59.72 \mathrm{AUC} /$ day, $\mathrm{p}<0.001)$. This finding was statistically significant. No difference was found when degree of exposure (high/moderate: $28.18 \mathrm{AUC} /$ day vs mild: $34.78 \mathrm{AUC} /$ day, $\mathrm{p}=0.395$ ) or job role (physician: 
Table 2 Broad characteristics among healthcare workers (HCWs) with positive antibody reactivity to SARS-CoV-2 spike in both phases

\begin{tabular}{|c|c|c|c|c|}
\hline & Overall & $\begin{array}{l}\text { Asymptomatic } \\
\text { for SARS-CoV-2 } \\
\text { infection } \\
\end{array}$ & $\begin{array}{l}\text { Symptomatic for } \\
\text { SARS-CoV-2 infection }\end{array}$ & $P$ value \\
\hline & $n=68$ & $n=11$ & $n=57$ & \\
\hline Age, mean $( \pm S D)$ & $42.9( \pm 1.45)$ & $44.5( \pm 3.8)$ & $42.6( \pm 1.6)$ & 0.557 \\
\hline Female, n (\%) & $40(58.8)$ & $6(54.5)$ & $34(40.4)$ & 0.502 \\
\hline Race & & & & 0.753 \\
\hline Latinx & $21(30.9 \%)$ & $3(27.3 \%)$ & $18(31.6 \%)$ & \\
\hline Asian & $18(26.5 \%)$ & $3(27.3 \%)$ & $18(26.3 \%)$ & \\
\hline Black & $15(22.1 \%)$ & $3(27.3 \%)$ & $12(21.1 \%)$ & \\
\hline White & $10(14.7 \%)$ & $2(18.2 \%)$ & $8(14.0 \%)$ & \\
\hline Other & $4(5.8 \%)$ & $0(0 \%)$ & $4(7.0 \%)$ & \\
\hline \multicolumn{5}{|l|}{ Comorbidities } \\
\hline Hypertension & $13(19.1 \%)$ & $2(18.2 \%)$ & $11(19.3 \%)$ & 0.650 \\
\hline Diabetes & $6(8.8 \%)$ & $0(0 \%)$ & $6(10.5 \%)$ & 0.332 \\
\hline COPD and asthma & $13(19.1 \%)$ & $1(9.1 \%)$ & $12(21.1 \%)$ & 0.326 \\
\hline Number of symptoms, median (IQR) & - & - & $4.0(2.0-5.0)$ & \\
\hline \multicolumn{5}{|l|}{ Length of symptoms } \\
\hline$<7$ days & - & - & $19(33.3 \%)$ & \\
\hline $7-14$ days & - & - & $12(21.1 \%)$ & \\
\hline$>14$ days & - & - & $26(45.6 \%)$ & \\
\hline Degree of HCW exposure & & & & 0.492 \\
\hline High and moderate & $16(23.5 \%)$ & $2(18.2 \%)$ & $14(24.6 \%)$ & \\
\hline Minor & $52(76.5 \%)$ & $9(81.8 \%)$ & $43(75.4 \%)$ & \\
\hline Community exposure & $19(27.9 \%)$ & $3(27.3 \%)$ & $16(28.1 \%)$ & 0.635 \\
\hline Household exposure & $17(25.4 \%)$ & $3(27.3 \%)$ & $14(24.6 \%)$ & 0.557 \\
\hline Use of face mask outside of hospital & $58(85.3 \%)$ & $9(81.8 \%)$ & 49 (86.0\%) & 0.722 \\
\hline Principal means of transportation & & & & 0.663 \\
\hline Public & $33(48.5 \%)$ & $6(54.5 \%)$ & $27(47.7 \%)$ & \\
\hline Private & $35(51.5 \%)$ & $5(45.5 \%)$ & $30(52.6 \%)$ & \\
\hline Nature of work & & & & 0.502 \\
\hline Physician & $29(42.6 \%)$ & $4(36.4 \%)$ & $25(43.9 \%)$ & \\
\hline Nurse & $15(22.1 \%)$ & $2(18.2 \%)$ & $13(22.8 \%)$ & \\
\hline Other & $24(35.3 \%)$ & $5(45.5 \%)$ & $19(33.3 \%)$ & \\
\hline Hospital areas work in & & & & 0.288 \\
\hline Emergency department/inpatient units & $32(47.1 \%)$ & $6(54.5 \%)$ & $26(45.6 \%)$ & \\
\hline Ambulatory care/clinics & $9(13.2 \%)$ & $2(18.2 \%)$ & $7(12.3 \%)$ & \\
\hline Inpatient and outpatient setting & $18(26.5 \%)$ & $3(27.3 \%)$ & $15(26.3 \%)$ & \\
\hline Administration/non-clinical care areas & $9(13.2 \%)$ & $0(0 \%)$ & $9(15.8 \%)$ & \\
\hline \multicolumn{5}{|l|}{ Anti-spike reactivity (AUC) } \\
\hline Reactivity in phase 1, g-mean (IQR) & $6590(5165-8410)$ & $5803(2825-11920)$ & $6754(5177-8812)$ & 0.647 \\
\hline Days from symptoms to first test, mean $( \pm S D)$ & - & - & $47.7( \pm 1.9)$ & \\
\hline Reactivity in phase 2, g-mean (IQR) & $2226(1824-2718)$ & $2382(1494-3797)$ & $2198(1753-2755)$ & 0.980 \\
\hline Days from symptoms to second test & & & $174.5( \pm 4.1)$ & \\
\hline Rate of decay, g-mean (IQR) & $31.14(22.11-43.87)$ & $23.42(8.45-64.93)$ & $32.96(22.73-47.82)$ & 0.382 \\
\hline
\end{tabular}

Continuous variables are expressed as mean (SD) or IQR, categorical variables as $n(\%)$.

AUC, area under the curve; COPD, chronic obstructive pulmonary disease; g-mean, geometric mean. 


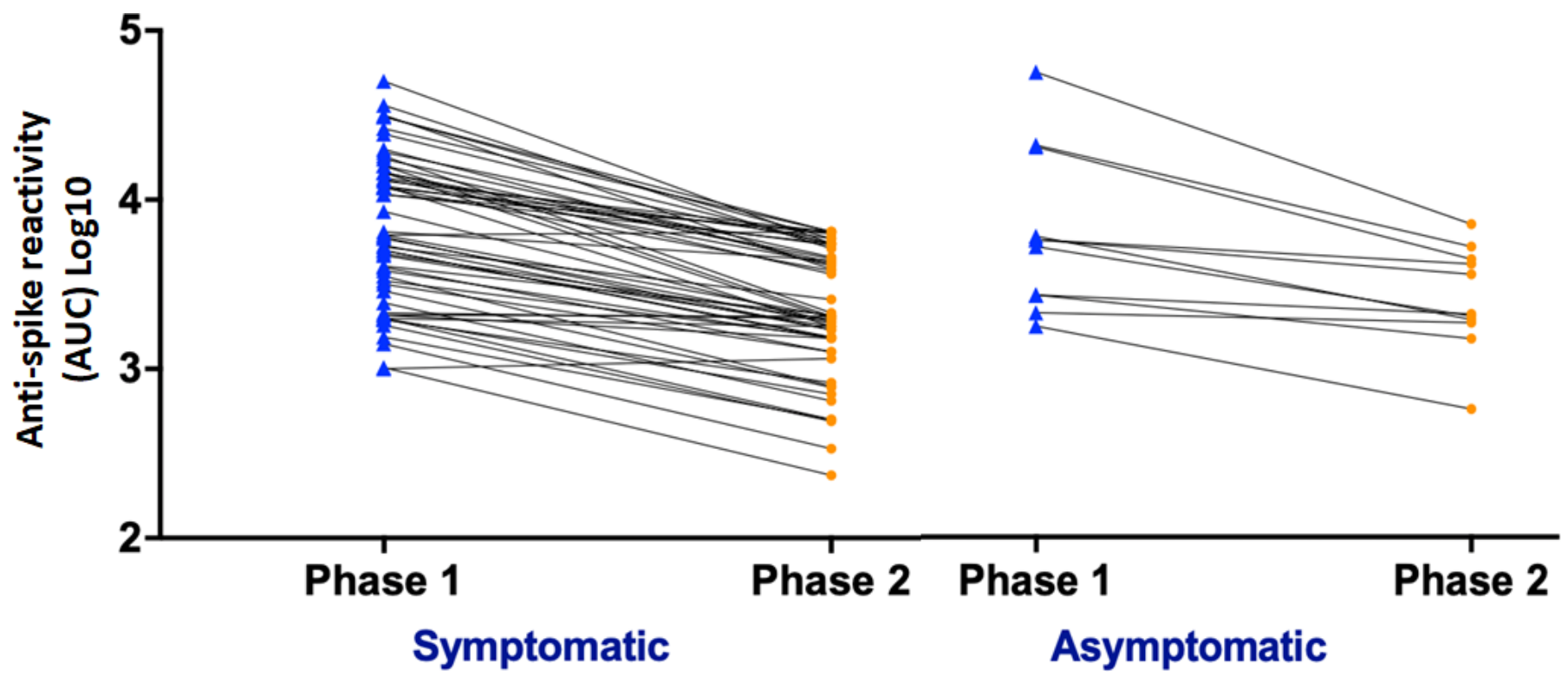

Figure 2 Antibody levels from phase 1 in specimens obtained early during the pandemic (May 2020) and phase 2 in follow-up visit (August-October 2020) are shown for symptomatic and asymptomatic participants. AUC, area under the curve.

29.57 AUC/day vs nurse: 53.59 AUC/day vs other: 26.83 AUC/day; $\mathrm{p}=0.361$ ) was compared with rate of decay.

Predictors of rate of decay from phase 1 to phase 2 of anti-S antibodies

Multiple linear regression analysis to predict the rate of decay with respect to age, BCG vaccination, number of symptoms and phase $1(\log 10)$ anti-S antibody titres is shown in table 3 . On the basis of a linear regression model that included the participants' age, history of BCG vaccination, total number of COVID-19 symptoms and the phase 1 concentration of $\log 10 \mathrm{~S}$ antibody titres, the estimated change (decay) was 23.6 AUC/day when age was centred at median (42.6 years), there was positive history of BCG vaccinations, the total number of COVID-19 symptoms were centred at a median of 4 and the geometric mean of the $\log 10 \mathrm{~S}$ antibody titre was 3.78 .

\section{DISCUSSION}

With the COVID-19 pandemic showing no signs of abating, HCWs at the epicentre are at risk of infection due to occupational exposure as well as community exposure. Sero-surveillance is the foundation for determining the scale and rate of exposures. With a multitude of serological assays getting emergency use approval from the Food and Drug Administration, interpretation of the results of these assays and their clinical significance remains challenging. It is critical to understand the timing of the antibody response for acute interpretation. Confidence in analytical specificity of the assay is a critical requirement in measurement of the specific antibody responses. Recent studies have confirmed that anti-S titres especially anti-RBD titres can serve as surrogates for virus neutralisation. ${ }^{31}{ }^{32}$ The Abbott SARS-CoV-2 IgG assay

\begin{tabular}{|c|c|c|c|c|c|c|c|c|c|c|c|c|}
\hline ELISA reactivity in & $\mathrm{R}$ & 1 & & & & & & & & & & \\
\hline Phase 1 (Log10) & Sig. & - & & & & & & & & & & \\
\hline \multirow{2}{*}{ Age } & $\mathrm{R}$ & $0.269^{* *}$ & 1 & & & & & & & & & \\
\hline & Sig. & 0.001 & - & & & & & & & & & \\
\hline \multirow{2}{*}{ Gender } & $\mathrm{R}$ & 0.106 & 0.050 & 1 & & & & & & & & \\
\hline & Sig. & 0.209 & 0.552 & - & & & & & & & & \\
\hline \multirow{2}{*}{ Comorbidities } & $R$ & 0.130 & $0.468^{* *}$ & 0.045 & 1 & & & & & & & \\
\hline & Sig. & 0.123 & 0.000 & 0.596 & - & & & & & & & \\
\hline \multirow{2}{*}{ BCG vaccine } & $\mathrm{R}$ & 0.046 & 0.014 & -0.129 & 0.084 & 1 & & & & & & \\
\hline & Sig. & 0.585 & 0.869 & 0.125 & 0.317 & - & & & & & & \\
\hline \multirow{2}{*}{ Fever } & $\mathrm{R}$ & $0.319^{* *}$ & 0.024 & -0.089 & 0.018 & 0.060 & 1 & & & & & \\
\hline & Sig. & 0.000 & 0.777 & 0.292 & 0.828 & 0.479 & - & & & & & \\
\hline \multirow{2}{*}{ URS } & $\mathrm{R}$ & $0.278^{* *}$ & 0.039 & 0.059 & 0.069 & $-0.214^{*}$ & $0.464^{* *}$ & 1 & & & & \\
\hline & Sig. & 0.001 & 0.645 & 0.486 & 0.413 & 0.010 & 0.000 & - & & & & \\
\hline \multirow{2}{*}{ Gl symptoms } & $\mathrm{R}$ & $0.204^{*}$ & 0.030 & 0.068 & 0.029 & 0.024 & $0.344^{* *}$ & $0.291^{* *}$ & 1 & & & \\
\hline & Sig. & 0.015 & 0.723 & 0.423 & 0.733 & 0.775 & 0.000 & 0.000 & - & & & \\
\hline \multirow{2}{*}{ Number of symptoms } & $\mathrm{R}$ & $0.310^{* *}$ & -0.015 & 0.070 & 0.026 & 0.019 & $0.708^{* *}$ & $0.665^{* *}$ & $0.630^{* *}$ & 1 & & \\
\hline & Sig. & 0.000 & 0.856 & 0.405 & 0.762 & 0.825 & 0.000 & 0.000 & 0.000 & - & & \\
\hline \multirow{2}{*}{ Days of symptoms } & $\mathrm{R}$ & $0.434^{* *}$ & 0.036 & 0.019 & 0.121 & -0.038 & $0.422^{* *}$ & $0.605^{* *}$ & $0.347^{* *}$ & $0.681^{* *}$ & 1 & \\
\hline & Sig. & 0.000 & 0.671 & 0.817 & 0.151 & 0.656 & 0.000 & 0.000 & 0.000 & 0.000 & - & \\
\hline \multirow{3}{*}{$\begin{array}{l}\text { Degree of } \mathrm{HCW} \\
\text { exposure }\end{array}$} & $\mathrm{R}$ & -0.145 & $-0.215^{* *}$ & $-0.217^{* *}$ & $-0.177^{\circ}$ & 0.017 & 0.017 & 0.034 & 0.000 & 0.039 & -0.085 & 1 \\
\hline & Sig. & 0.083 & 0.010 & 0.009 & 0.034 & 0.838 & 0.844 & 0.690 & 0.998 & 0.640 & 0.314 & - \\
\hline & & $\begin{array}{c}\text { ELISA reactivity } \\
\text { in Phase } 1 \\
\text { (Log10) }\end{array}$ & Age & Gender & Comorbidities & BCG vaccine & Fever & URS & Gl symptoms & $\begin{array}{l}\text { Number of } \\
\text { symptoms }\end{array}$ & $\begin{array}{c}\text { Days of } \\
\text { symptoms }\end{array}$ & $\begin{array}{l}\text { Degree of HCW } \\
\text { exposure }\end{array}$ \\
\hline
\end{tabular}

Figure 3 Simple correlation analysis of HCWs with positive reactivity for anti-spike antibody in phase 1 with baseline characteristics and symptoms. ${ }^{\star \star}$ Correlation is significant at the 0.01 level; *correlation is significant at the 0.05 level. Gl, gastrointestinal symptoms (nausea, vomit, diarrhoea); HCW, healthcare worker; URS, upper respiratory symptoms. 


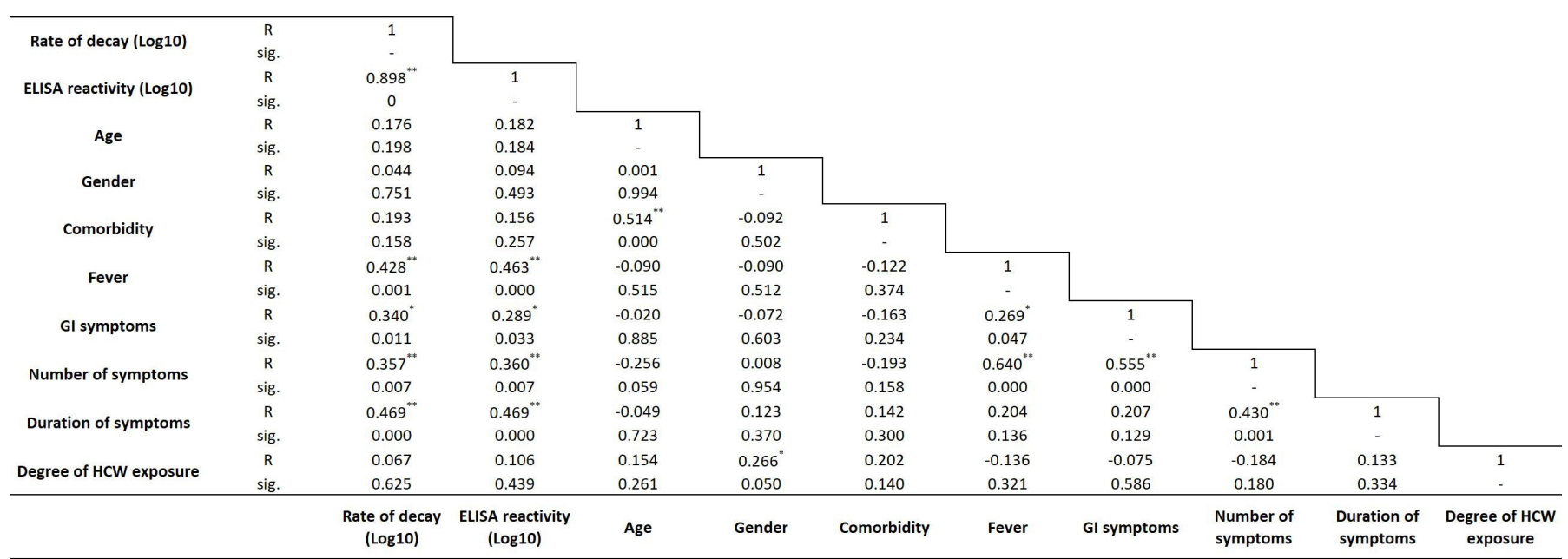

Figure 4 Simple correlation analysis of rate of decay of anti-spike antibodies between both phases with baseline characteristics and symptoms. ${ }^{*}$ Correlation is significant at the 0.01 level; *correlation is significant at the 0.05 level. GI, gastrointestinal symptoms (nausea, vomit, diarrhoea); HCW, healthcare worker.

that targets antibodies to the $\mathrm{N}$ has a reported specificity and sensitivity of greater than $99 \%$ at 14 days or more following symptom onset and these measurements are not indicative or correlated to virus neutralisation titres. ${ }^{33}$ In comparison, the MSH ELISA targets the full-length S protein including RBD, a major target for neutralising antibodies and has demonstrated excellent correlation to virus neutralisation. ${ }^{1126}$ Longitudinal measurements of antibody levels have revealed that anti-N and anti-S IgG
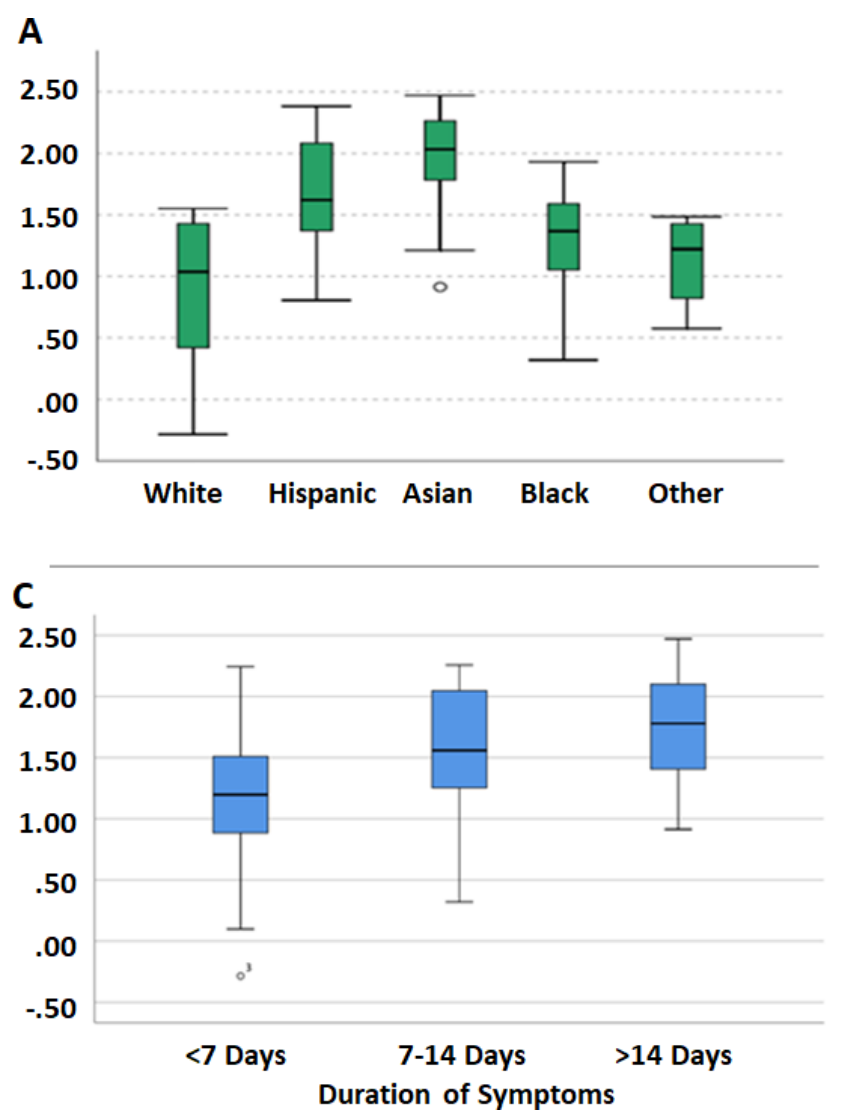

antibodies continue to increase until the third week postsymptoms, and an approach that combines the detection of both of these antibodies would precisely detect almost $100 \%$ of all infectious exposures. ${ }^{34}$ In our study, the mean number of days after symptoms to testing in phase 1 was 47 days, suggesting a higher likelihood of accuracy of the used assay.

Longitudinal blood sampling among HCWs working at a public hospital which was at the epicentre of the
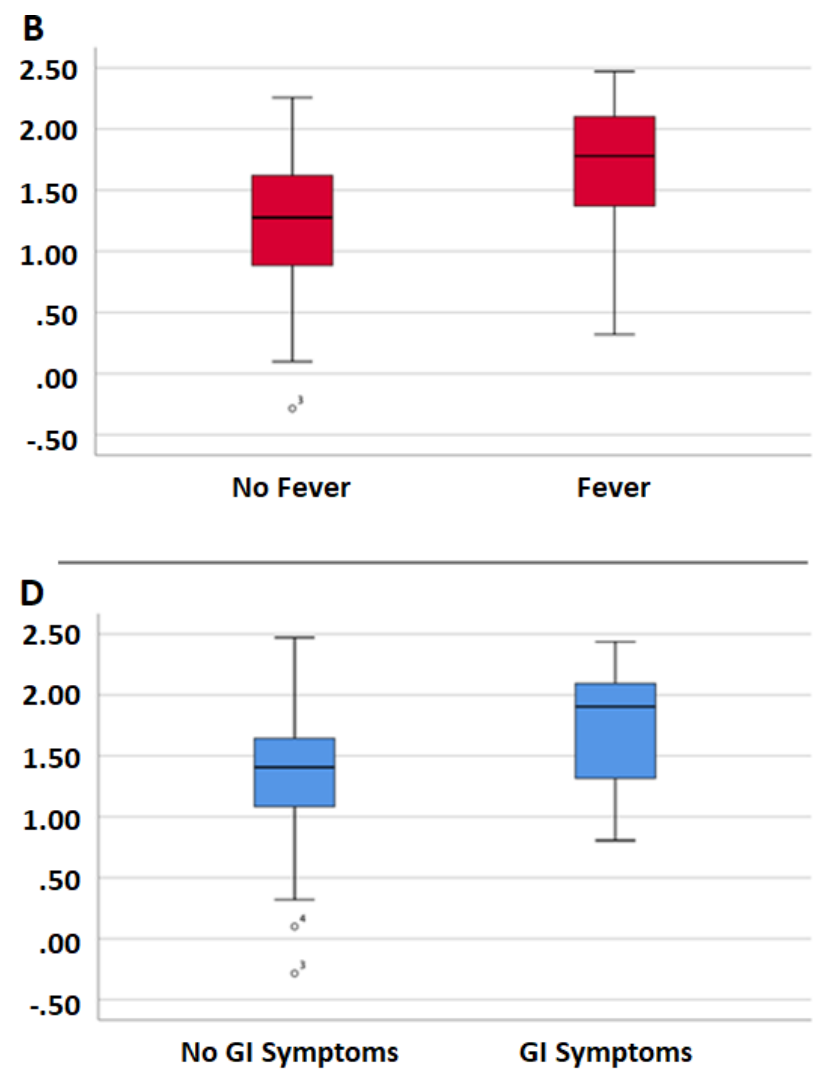

Figure 5 (A-D) Paired comparison between rate of decay of anti-spike antibody titres and patient characteristics. Gl, gastrointestinal. 
Table 3 Multiple linear regression analysis of rate of decay for anti-spike antibodies between phase 1 and phase 2

\begin{tabular}{|c|c|c|c|c|c|c|c|}
\hline \multirow[b]{2}{*}{ Rate of decay (log10) } & \multirow[b]{2}{*}{ B } & \multicolumn{2}{|c|}{$95.0 \% \mathrm{Cl}$ for $\mathrm{B}$} & \multirow[b]{2}{*}{ SE B } & \multirow[b]{2}{*}{ B } & \multirow[b]{2}{*}{$\mathbf{R}^{2}$} & \multirow[b]{2}{*}{$\Delta \mathrm{R}^{2}$} \\
\hline & & LL & UL & & & & \\
\hline Model & & & & & & 0.83 & 0.82 \\
\hline Age (per 10-year change) & 0.014 & -0.005 & 0.007 & 0.002 & 0.030 & & \\
\hline BCG vaccination & $0.131^{*}$ & 0.030 & 0.310 & 0.046 & 0.121 & & \\
\hline ELISA reactivity (log10) & $1.159^{*}$ & 1.050 & 1.419 & 0.059 & 0.916 & & \\
\hline
\end{tabular}

${ }^{*} \mathrm{P}<0.05$.

B, standardised coefficient; B, unstandardised regression coefficient; LL, lower limit; $R^{2}$, coefficient of determination; $\mathbf{\Delta} \mathrm{R}^{2}$, adjusted $\mathrm{R}^{2}$; SE B, SE of the coefficient; UL, upper limit.

pandemic in NYC allowed for analysis of kinetics of anti-S and anti-N antibody responses. At 2 months after the first surge of infections, anti-N antibodies were detected in $27 \%$ and anti-S antibodies in $28 \%$ of participating HCWs. After an interval of 4 months, it is not surprising to note that among the participants who returned, $26 \%$ remained positive for anti-N antibodies, while $31 \%$ of the previously anti-N antibody-positive subjects tested negative in phase 2. On the other hand, a similar analysis of the anti-S antibody levels confirmed that all the previously positive retested subjects continued to remain positive, although with lower titres. That being said, we acknowledge that the decline of $\mathrm{N}$ antibodies in our cohort could be due to the Abbott assay being less sensitive to describe the dynamics of $\mathrm{N}$ antibodies over time compared with other assays, like Roche, Siemens and Diasorin. Muecksch et al demonstrated in their longitudinal analysis of clinical serology assay performance among COVID-19 convalescents that there is a difference in diagnostic performance among various serological assays. ${ }^{32}$

COVID-19-related symptoms were significantly associated with positive anti-S antibodies in both phases, with a similar association with longer duration ( $>14$ days) of symptoms. Previous studies have demonstrated a lower level of IgG response among patients without symptoms or with mild symptoms compared with those with severe and critical disease. ${ }^{35}{ }^{36} \mathrm{~A}$ comparison of symptomatic versus asymptomatic subjects who tested positive for anti-S antibodies in both phases confirmed that the rate of decay of anti-S antibody titres were faster in the symptomatic cohort than the asymptomatic subjects, which was seen also in the anti-N antibody kinetics. We observed a faster decay in this group with a lower titre of anti-S antibodies in phase 2 compared with the asymptomatic cohort (though the difference was not statistically significant). This could additionally be supported by the finding of fever and GI symptoms contributing to faster decay. Similar results of decreasing neutralising antibody titre in symptomatic than asymptomatic patients were observed by Choe $e t a l .{ }^{37}$

Positive correlations for age, presence of fever, upper respiratory symptoms, GI symptoms, total number and duration of symptoms were observed with increased levels of anti-S titres at phase 1. Similar results of neutralising antibody titres were also observed by Boonyaratanakornkit et $a l^{38}$ where they showed higher levels of neutralising antibody titres were significantly associated with male gender, older adults, higher disease severity and shorter interval from recovery. Based on a linear regression model with age centred at median (42.6 years), positive history of BCG vaccination, the total number of COVID-19 symptoms centred at a median of 4 and the geometric mean of the $\log 10$ anti-S antibody titre at 3.78, we observed that the rate of decay of these antibody titres was 23.6 AUC/ day. Evaluation of other characteristics with rate of decay between phase 1 and phase 2 showed a faster reduction in titres in Asian participants and in those with fever and GI symptoms. A slower decrease was noted among patients with shorter duration $(<7$ days $)$ of symptoms, with no other significant correlation noted with any other baseline demographics or clinical characteristics.

As described above, higher antibody titres are associated with a larger number of symptoms, longer duration of symptoms and-as described by others as well-disease severity in general. We also found that higher initial antibody titres were associated with faster antibody decay during the two time points. Initial antibody responses are driven by short-lived plasmablasts, which decay after a few days after producing massive amounts of antibody. IgG has a relatively long half-life of approximately 3 weeks, but decay is inevitable since the plasmablasts initially producing it disappear. Usually, titres then drop until they reach relatively stable levels of antibody which are maintained by long-lived plasma cells in the bone marrow. ${ }^{19}$ The two time points described in this study represent the initial peak response and likely the stable level after the initial decay. We found that individuals with higher initial titres had a faster decay rate during the observation period, meaning the difference between peak and stable, long-lived antibody levels was larger. This indicates that there is likely no direct correlation between the magnitude of the initial expansion of plasmablasts and the number of long-lived plasma cells that migrate to the bone marrow. It is critical to recognise that steady 
state antibody titres are similar between the symptomatic and asymptomatic subgroups, suggesting that midterm humoral protection might be similar after infection regardless of disease severity.

Our study has the following limitations: first, being a single-centre study with a small convenience sampling method that included a smaller number of participants in phase 2 of the study. Following the pandemic, the HCWs who had volunteered from around the country were transferred back and thus lost to follow-up. While this did decrease the overall sample size, it is notable that the rates of positive and negative results remained proportional. Second, there is a possibility of recall bias in the participant's responses on the online survey. Lastly, the study findings can underestimate rates of prior infections based on timing of the testing given that antibodies are only transiently detectable following infection.

In conclusion, findings from this study are similar to other studies that have reported that higher magnitude of anti-S titres may correlate with protection against reinfection, in spite of the observed decay in the antibody levels. ${ }^{20} 21$ Nevertheless, further studies to evaluate the longevity of immunity, especially in context of widespread administration of S-based vaccine among HCWs, would be important in predicting herd immunity to COVID-19 infections.

Acknowledgements This paper is dedicated to our colleague Dr Bo Yu who had been a major part of our research team and his contributions will be remembered by the scientific community. The authorship is structured in first-last-author emphasis. We thank the COVID-19 Testing Tent staff for their invaluable assistance with this study with testing and accommodation of study participants for phase 2: Patrick C McNeil PA-C MPAS; Aney D Patel PA-C MPAS; and Megan Corley DNP ANP-BC. We thank the nursing staff for their commitment and support with the workflow, especially Karen Philip and Kenisha Williamson with others; additionally, the Registration (Lexus Gonzalez and Taj Washington) and Patient Care Associate (Eva Penn) that assisted the research team. We also thank the Occupational Health Services for accommodating the research team during project completion. The Clinical Laboratory staff played a part in allocating resources for Abbott Architect usage: Dior Ndao and Ayman Elshamshery. We thank the study participants who were essential healthcare workers, who volunteered to follow up in this protocol.

Contributors VM, MAS and UV designed the study. JMC, MAS, BY and VPG analysed the data. EV and MG assisted with participant follow-up and coordination with the assistance of AP, UV, VM and MAS. The Mount Sinai Health System team, JMC and FK, performed the measurements for anti-spike and anti-RBD antibodies. VM, UV and AP were responsible for the clinical care of the research participants and supervised the day-to-day operation and coordination of the study by MK, VD, MAS, BY, VPG, MG and EV. VM, VPG, MAS and FK wrote the manuscript and are the guarantors of this work and have full access to all data in the study and take responsibility for the integrity of the data and the accuracy of the data analysis. All authors critically revised the draft and approved the final manuscript.

Funding The authors have not declared a specific grant for this research from any funding agency in the public, commercial or not-for-profit sectors.

Competing interests FK is listed as a co-inventor on a patent application filed by the Icahn School of Medicine at Mount Sinai relating to SARS-CoV-2 serological assays and NDV-based SARS-CoV-2 vaccines. Mount Sinai has spun out a company, Kantaro, to market serological tests for SARS-CoV-2. FK has consulted for Merck and Pfizer (before 2020), and is currently consulting for Seqirus and Avimex. FK's Krammer laboratory is also collaborating with Pfizer on animal models of SARS-CoV-2.

Patient consent for publication Not required.

Ethics approval The study protocol was approved by the Institutional Review Board approval (IRB \# 20-009, Lincoln Medical Center, Office of the Institutional
Review Board approved as per 45 CFR 46 \& 21 CFR50,56 under a full board committee and gave its approval on 28 April 2020). All participants provided written informed consent for the use of their data.

Provenance and peer review Not commissioned; externally peer reviewed.

Data availability statement All data relevant to the study are included in the article or uploaded as supplemental information. Data are available on request from the corresponding author as deidentified participant data. All data relevant to the study has been included in the article.

Supplemental material This content has been supplied by the author(s). It has not been vetted by BMJ Publishing Group Limited (BMJ) and may not have been peer-reviewed. Any opinions or recommendations discussed are solely those of the author(s) and are not endorsed by BMJ. BMJ disclaims all liability and responsibility arising from any reliance placed on the content. Where the content includes any translated material, BMJ does not warrant the accuracy and reliability of the translations (including but not limited to local regulations, clinical guidelines, terminology, drug names and drug dosages), and is not responsible for any error and/or omissions arising from translation and adaptation or otherwise.

Open access This is an open access article distributed in accordance with the Creative Commons Attribution Non Commercial (CC BY-NC 4.0) license, which permits others to distribute, remix, adapt, build upon this work non-commercially, and license their derivative works on different terms, provided the original work is properly cited, appropriate credit is given, any changes made indicated, and the use is non-commercial. See: http://creativecommons.org/licenses/by-nc/4.0/.

\section{ORCID iDs}

Vidya Menon http://orcid.org/0000-0003-1411-3420

Masood A Shariff http://orcid.org/0000-0003-4082-4066

\section{REFERENCES}

1 Ou X, Liu Y, Lei X, et al. Characterization of spike glycoprotein of SARS-CoV-2 on virus entry and its immune cross-reactivity with SARS-CoV. Nat Commun 2020;11:1620.

2 Walls AC, Park Y-J, Tortorici MA, et al. Structure, function, and antigenicity of the SARS-CoV-2 spike glycoprotein. Cell 2020;181:281-92.

3 Premkumar L, Segovia-Chumbez B, Jadi R, et al. The receptor binding domain of the viral spike protein is an immunodominant and highly specific target of antibodies in SARS-CoV-2 patients. Sci Immunol 2020;5:eabc8413.

$4 \mathrm{Ni}$ L, Ye F, Cheng M-L, et al. Detection of SARS-CoV-2-Specific humoral and cellular immunity in COVID-19 convalescent individuals. Immunity 2020;52:971-7.

5 lyer AS, Jones FK, Nodoushani A, et al. Persistence and decay of human antibody responses to the receptor binding domain of SARS-CoV-2 spike protein in COVID-19 patients. Sci Immunol 2020;5:eabe0367.

6 Cong Y, Ulasli M, Schepers $\mathrm{H}$, et al. Nucleocapsid protein recruitment to replication-Transcription complexes plays a crucia role in coronaviral life cycle. J Virol 2020;94:e01925-19.

7 Burbelo PD, Riedo FX, Morishima C, et al. Detection of nucleocapsid antibody to SARS-CoV-2 is more sensitive than antibody to spike protein in COVID-19 patients. medRxiv 2020. doi:10.1101/2020.04.2 0.20071423. [Epub ahead of print: 24 Apr 2020].

8 Long Q-X, Liu B-Z, Deng H-J, et al. Antibody responses to SARSCoV-2 in patients with COVID-19. Nat Med 2020;26:845-8.

9 İnandıklığlu N, Akkoc T. Immune responses to SARS-CoV, MERSCoV and SARS-CoV-2. Adv Exp Med Biol 2020;1288:5-12.

10 Chaudhuri S, Thiruvengadam R, Chattopadhyay S, et al. Comparative evaluation of SARS-CoV-2 IgG assays in India. $J$ of Virol 2020;131:104609.

11 Wajnberg A, Amanat F, Firpo A, et al. Robust neutralizing antibodies to SARS-CoV-2 infection persist for months. Science 2020;370:1227-30.

12 Crawford KHD, Dingens AS, Eguia R, et al. Dynamics of neutralizing antibody titers in the months after severe acute respiratory syndrome coronavirus 2 infection. J Infect Dis 2021;223:197-205.

13 Luchsinger LL, Ransegnola BP, Jin DK, et al. Serological assays estimate highly variable SARS-CoV-2 neutralizing antibody activity in recovered COVID-19 patients. J Clin Microbiol 2020;58. doi:10.1128/ JCM.02005-20. [Epub ahead of print: 1811 2020].

14 lyer AS, Jones FK, Nodoushani A, et al. Dynamics and significance of the antibody response to SARS-CoV-2 infection. medRxiv 2020. doi: 10.1101/2020.07.18.20155374. [Epub ahead of print: 20 Jul 2020]. 
15 Isho B, Abe KT, Zuo M, et al. Persistence of serum and saliva antibody responses to SARS-CoV-2 spike antigens in COVID-19 patients. Sci Immunol 2020;5:eabe5511.

16 Wu F, Wang A, Liu M, et al. Neutralizing antibody responses to SARS-CoV-2 in a COVID-19 recovered patient cohort and their implications. medRxiv 2020.

17 Seow J, Graham C, Merrick B, et al. Longitudinal observation and decline of neutralizing antibody responses in the three months following SARS-CoV-2 infection in humans. Nat Microbiol 2020;5:1598-607.

18 Grandjean L, Saso A, Torres A. Humoral response dynamics following infection with SARS-CoV-2. medRxiv 2020.

19 Turner JS, Kim W, Kalaidina E, et al. SARS-CoV-2 infection induces long-lived bone marrow plasma cells in humans. Res Sq 2020. doi:10.21203/rs.3.rs-132821/v1. [Epub ahead of print: 31 Dec 2020].

20 Lumley SF, O'Donnell D, Stoesser NE, et al. Antibody status and incidence of SARS-CoV-2 infection in health care workers. $N$ Engl J Med 2021;384:533-40.

21 Hall V, Foulkes S, Charlett A. Do antibody positive healthcare workers have lower SARS-CoV-2 infection rates than antibody negative healthcare workers? large multi-centre prospective cohort study (the siren study), England: June to November 2020. medRxiv 2021.

22 Self WH, Tenforde MW, Stubblefield WB, et al. Seroprevalence of SARS-CoV-2 among frontline health care personnel in a multistate hospital network - 13 academic medical centers, April-June 2020. MMWR Morb Mortal Wkly Rep 2020;69:1221-6.

23 Moscola J, Sembajwe G, Jarrett M, et al. Prevalence of SARS-CoV-2 antibodies in health care personnel in the new York City area. JAMA 2020;324:893-5.

24 Venugopal U, Jilani N, Rabah S, et al. SARS-CoV-2 seroprevalence among health care workers in a New York City Hospital: a crosssectional analysis during the COVID-19 pandemic. Int $J$ Infect Dis 2021:102:63-9.

25 Hamilton F, Muir P, Attwood M, et al. Kinetics and performance of the Abbott architect SARS-CoV-2 IgG antibody assay. J Infect 2020;81:e7-9.

26 Amanat F, Stadlbauer D, Strohmeier S, et al. A serological assay to detect SARS-CoV-2 seroconversion in humans. Nat Med 2020;26:1033-6.
27 Stadlbauer D, Amanat F, Chromikova V, et al. SARS-CoV-2 seroconversion in humans: a detailed protocol for a serological assay, antigen production, and test setup. Curr Protoc Microbiol 2020;57:e100.

28 Amanat F, Stadlbauer D, Strohmeier S, et al. A serological assay to detect SARS-CoV-2 seroconversion in humans. Nat Med 2020;26:1033-6.

29 Stadlbauer D, Tan J, Jiang K, et al. Repeated cross-sectional sero-monitoring of SARS-CoV-2 in New York City. Nature 2021:590:146-50.

30 Garcia M, Lipskiy N, Tyson J, et al. Centers for disease control and prevention 2019 novel coronavirus disease (COVID-19) information management: addressing national health-care and public health needs for standardized data definitions and codified vocabulary for data exchange. J Am Med Inform Assoc 2020;27:1476-87.

31 Therrien C, Serhir B, Bélanger-Collard M. Multicenter evaluation of the clinical performance and the neutralizing antibody activity prediction properties of ten high throughput serological assays used in clinical laboratories. J Clin Microbiol 2020;59:e02511-20.

32 Muecksch $\mathrm{F}$, Wise $\mathrm{H}$, Batchelor $\mathrm{B}$, et al. Longitudinal serological analysis and neutralizing antibody levels in coronavirus disease 2019 convalescent patients. J Infect Dis 2021;223:389-98.

33 Rosadas C, Randell P, Khan M, et al. Testing for responses to the wrong SARS-CoV-2 antigen? Lancet 2020;396:e23.

34 Sun B, Feng Y, Mo X, et al. Kinetics of SARS-CoV-2 specific IgM and IgG responses in COVID-19 patients. Emerg Microbes Infect 2020;9:940-8.

35 Long Q-X, Tang X-J, Shi Q-L, et al. Clinical and immunological assessment of asymptomatic SARS-CoV-2 infections. Nat Med 2020;26:1200-4.

36 Wang $Y$, Zhang L, Sang L, et al. Kinetics of viral load and antibody response in relation to COVID-19 severity. J Clin Invest 2020;130:5235-44.

37 Choe PG, Kang CK, Suh HJ, et al. Waning antibody responses in asymptomatic and symptomatic SARS-CoV-2 infection. Emerg Infect Dis 2021;27:327-9.

38 Boonyaratanakornkit J, Morishima C, Selke S, et al. Clinical, laboratory, and temporal predictors of neutralizing antibodies to SARS-CoV-2 after COVID-19. medRxiv 2020. doi:10.1101/2020.10.0 6.20207472. [Epub ahead of print: 21 Oct 2020]. 